\title{
Selective Laser Melting of crack-free high density M2 HSS parts by baseplate pre-heating.
}

\author{
Karolien Kempen \\ Department of Mechanical Engineering \\ University of Leuven (KU Leuven) \\ 3001 Leuven, Belgium \\ Email: karolien.kempen@kuleuven.be
}

\author{
Jan Van Humbeeck \\ Dep. of Materials Engineering \\ University of Leuven (KU Leuven) \\ 3001 Leuven, Belgium \\ Email: jan.vanhumbeeck@kuleuven.be
}

Sam Buls

Dep. of Mechanical Engineering

University of Leuven (KU Leuven)

3001 Leuven, Belgium

Email: sam.buls@kuleuven.be

\author{
Bey Vrancken \\ Dep. of Materials Engineering \\ University of Leuven (KU Leuven) \\ 3001 Leuven, Belgium \\ Email: bey.vrancken@kuleuven.be
}

\author{
Lore Thijs \\ LayerWise nv \\ 3001 Leuven, Belgium \\ Email: lore.thijs@layerwise.com \\ Jean-Pierre Kruth \\ Dep. of Mechanical Engineering \\ University of Leuven (KU Leuven) \\ 3001 Leuven, Belgium
}

\begin{abstract}
Cracks and delamination, resulting from residual stresses are a barrier in the world of Additive Manufacturing and Selective Laser Melting (SLM) that prohibits the use of many metals in this field. By pre-heating the baseplate, thermal gradients are lowered and stresses can be reduced. In this work, some initial tests were performed with M2 High Speed Steel. The influence of pre-heating on density and mechanical and physical properties is investigated. The paper shows many promising results for the production of SLM parts in materials that are very sensitive to crack formation and delamination. When using a pre-heating of $200^{\circ} \mathrm{C}$, crack-free M2 HSS parts were produced with a relative density of $99.8 \%$.
\end{abstract}

\section{Introduction}

Selective Laser Melting (SLM) is a Laser Additive Manufacturing technique in which a three-dimensional product is built up in a layer-by-layer manner. Thin layers of powder are selectively scanned by a high-intensity laser. Due to this high laser energy input, the metal powder melts and consecutively consolidates upon cooling. By subsequently repeating these steps for all layers, a three-dimensional metal part is built up. Due to the layer-wise nature of the process, the production of complex near-net shape parts with internal cavities is enabled [1].

This high degree of geometrical freedom leads to the possibility to produce mould or die inserts (and other tools) with complex cavities like conformal cooling channels. These applications require a material with a high hardness and wear resistance. M2 High Speed Steel (HSS) is a material from the group of tool steels that maintains its high hardness, even at high temperatures (e.g. when cutting at high speeds). The chemical composition of M2 HSS is shown in Table 1.

However, the high hardness of this material goes hand in hand with a low ductility. The combination of a brittle material and a production process like SLM, that may induce high residual stresses, can easily cause problems like crack formation and delamination of the part from the baseplate.

Preliminary tests indicate that SLM of M2 HSS is nearly impossible without making changes to the process or the material. The high carbon content causes severe distortion of the tetragonal martensite crystal structure, leading to the high hardness. 
By comparison, 18Ni300 maraging steel relies on the formation of intermetallics to achieve high hardness and has a low carbon content. The martensite that is formed in $18 \mathrm{Ni} 300$ maraging steel is relatively soft and no cracking or delamination problems occur during SLM [2]. In EBM, an electron beam additive manufacturing technique for processing of metals, the powder bed is pre-heated and thermal gradients are lower. [3].

Literature has shown the possibility to process the M2 tool steel by laser based processes, and the effect of pre-heating on residual stresses. The work of Childs et.al. showed that the formation of a stable, crack-free single line track is possible in M2 tool steel, and a process window is defined for low scan speeds and low laser power [4]. Niu et.al. [5] showed the influence of scanning parameters on the density of M2 HSS two-dimensional surfaces. Since no three-dimensional parts were built up in this work, no cracks were formed.

In Abe et.al., a dual laser scanning system in which YAG and $\mathrm{CO}_{2}$ laser beams are offset a small amount from each other is proposed. It is considered that slow cooling or re-heating after melting can eliminate residual stress and improve the part's ductility [6]. The use of a pre-heating system to reduce thermal stresses has also shown its advantages in the work of Alimardani et al. [7], where the residual stresses were reduced by $22 \%$ in a stainless steel wall produced by direct metal deposition, by using a pre-heating up to $800 \mathrm{~K}$. Das et al. at the University of Texas developed a powder bed pre-heating system that reaches up to $1300{ }^{\circ} \mathrm{C}$ [8]. Initial tests at pre-heating temperatures of $350^{\circ} \mathrm{C}$ an $900^{\circ} \mathrm{C}$ showed that the influence of pre-heating on the wetting behavior is minimal [9]. In SLM of ceramics, Hagedorn et al. established crack-free parts with a CO2 laser pre-heating of $1700^{\circ} \mathrm{C}[10]$.

Numerical models for residual stresses are developed by Shiomi et.al. [11] and Mercelis et.al. [12]. It is however in measuring and eliminating these stresses that the major shortcomings lie.

\section{Experimental}

All SLM parts were produced on a Concept Laser M3 Linear machine in a protective Argon or Nitrogen atmosphere. The oxygen level is controlled to $<1 \%$. The machine is equipped with a $100 \mathrm{~W} \mathrm{Nd:YAG} \mathrm{laser} \mathrm{that} \mathrm{has} \mathrm{a} \mathrm{wavelength} \mathrm{of} 1.064$ $\mu \mathrm{m}$ and a laser beam diameter of $180 \mu \mathrm{m}(99 \%)$.

Test specimens consisted of blocks measuring $20 \times 20 \mathrm{~mm}^{2}$ with a total height of $10 \mathrm{~mm}$. All test parts were produced with a layer thickness of $30 \mu \mathrm{m}$, a laser power of $105 \mathrm{~W}$ (measured on the powder bed) and a hatch spacing of $128 \mu \mathrm{m}$. The range of scan speed is set from $250 \mathrm{~mm} / \mathrm{s}$ up to $550 \mathrm{~mm} / \mathrm{s}$. The island scanning strategy, patented by Concept Laser $\mathrm{GmbH}$ [13], consists of dividing the total scan area into smaller squares $(5 \times 5 \mathrm{~mm})$ and scanning these squares in a random manner. Between two successive layers, the scan vectors rotate $90^{\circ}$ in every island and the islands are shifted $1 \mathrm{~mm}$ in both $\mathrm{X}$ - and Y-direction.

In order to increase the density of the produced parts, re-melting can be applied [14]. This technique involves scanning every layer twice, before adding a new powder layer. In this research, re-melting of every layer was applied with a laser power of $105 \mathrm{~W}$, hatch spacing of $105 \mu \mathrm{m}$ and scan speed of $200 \mathrm{~mm} / \mathrm{s}$. The use of the re-melting scan strategy however, is very time-consuming as it almost doubles the production time. This is why this strategy is only used when nearly full density is required (i.e. in mechanical testing).

Gas atomized M2 HSS powder; produced by LPW [15] was used. SEM image in Figure 1 shows the spherical powder particles with some small satellite particles on the larger fraction. The size of the powder particles ranges from 15 to $45 \mu \mathrm{m}$ in diameter (based on the sieving method).

S urface roughness measurements were carried out on a Taylor Hobson Form Talysurf 120L. A probe (diameter $2 \mu \mathrm{m}$ ) scans a data length of $15 \mathrm{~mm}$. Ten lines on the top surface of the part are measured according to the ISO-standard 4288. It states that for the measured surface roughness no cut-off filter can be used. The arithmetic mean surface roughness $\left(R_{a}\right)$ is calculated.

The Archimedes principle was used to measure the density. A bulk density of conventional M2 HSS of $8.15 \mathrm{~kg} / \mathrm{dm}^{3}$ was used to calculate the relative density of the produced SLM parts.

Surface topology was investigated by a SEM Philips XL40.

To determine the mechanical properties, tensile and hardness tests were conducted. Flat tensile test parts with a gauge length of $32 \mathrm{~mm}$ and a thickness of $5 \mathrm{~mm}$ were produced with the parameters for optimal density. An Instron 4505 testing machine was used for tensile testing. Hardness was measured according to the Rockwell hardness scale. The parts were measured according to the ASTM E 92-65 standard. A $150 \mathrm{~kg}$ load was used and five indentations were made in each sample. The average hardness and a confidence interval of $95 \%$ were calculated.

$\mathrm{X}$-Ray diffraction patterns were measured by a Siemens D500 Goniometer using a Cr tube. 


\section{Results and Discussion}

\subsection{Problem statement}

When producing M2 HSS parts by Selective Laser Melting, high thermal stresses cause the parts to crack or delaminate from the baseplate, as shown in Figure 2. These thermal stresses need to be reduced in order to eliminate this cracking and to produce dense and qualitative parts in M2 HSS by SLM.

In SLM there are two mechanisms that may induce residual thermal stresses: (i) induced stresses in the solid substrate just underneath the present layer being melted and (ii) stresses due to the cool-down phase of the melted top layers.

The first phenomenon results from large thermal gradients in the solid material just underneath the laser spot (Figure 3). Due to the high temperature in the upper layers of the solid substrate, those upper layers will expand, while the colder underlying solidified layers will restrict this expansion. This induces compressive stresses $\sigma_{\text {comp }}$ in the upper layers of the substrate that may rise above the yield strength of the material and cause plastic upsetting in those upper layers. When the yield strength is reached, the compressive stresses in the material cause plastic deformation $\sigma_{p l}$ of the upper layers. When those plastically deformed layers cool down, their compressive state is converted into residual tensile stresses $\sigma_{\text {tens }}$. Those residual stresses may induce cracking of the part.

In the second phenomenon, the melted top layers tend to shrink due to thermal contraction. This deformation is again prohibited by the underlying layers, thus introducing tensile stresses in the top layer, and compressive stresses below. The latter effect is the most pronounced.

From previous work on reduction of thermal stresses by Mercelis et.al [12] and Shiomi et.al [11], it is shown that so far, the best way to reduce thermal stresses is uniform pre-heating of the baseplate. Also, this work shows that there are more stresses built up in a part with higher density. Pores relax the residual stresses as they do not contain internal stresses.

\subsection{Pre-heating element}

Figure 4 shows the schematic overview of the heating module that was designed and installed on the Concept Laser M3 machine. The heating element itself (red) is installed underneath the building platform, on top of which the baseplate is mounted. The heating element is surrounded by insulation material so the rest of the building module does not heat up. It is cricital that both the mechanical set-up (e.g. the building plane determines the layer thickness) and the optical set-up (determination of the laser path and focus) do not expand or damage due to excessive heat.

The temperature of the baseplate can be controlled by the resistive heat element. A proportional and integral control loop (PI-controller) controls the power to the heat element to achieve a desired temperature on the baseplate within a range of $\pm 2^{\circ} \mathrm{C}$. This pre-heating module was designed and developed at the University of Leuven (KU Leuven) and can easily be disassembled.

\subsection{Crack formation}

In order to build crack-free parts with high density, pre-heating of the baseplate was applied to lower the thermal gradient during the process. Figure 5 shows 3 samples which were built using three different pre-heating temperatures $\left(90^{\circ} \mathrm{C}(\mathrm{left})\right.$, $150^{\circ} \mathrm{C}$ (middle) and $200^{\circ} \mathrm{C}$ (right)). It can be seen that the higher pre-heating temperature results in less crack formation. All parts in Figure 5 were produced to have a density of $99.3 \%$, hereby eliminating the influence of density on stress relaxation and crack formation. When observing the cross-section of the crack-free part under LOM and SEM, it is shown that the part does not contain micro-cracks either.

Laser re-melting is a technique sometimes used to improve the properties of SLM parts [14,16]. It consists of re-melting the most recent layer before adding a new layer of powder. Re-melting may improve part density, microstructure and top surface quality. However, when re-melting every layer of M2 parts, the formation of cracks becomes more likely due to:

1. The increase of density: re-melting increases the density of the part, and thus enhances crack formation.

2. The higher cooling rate: re-melting every layer involves a higher cooling rate because solid material has a higher heat conductivity than powder material. Because of this higher cooling rate, more martensite phase will be formed, which is more brittle than ferrite phase. While being submitted to the same stresses, the brittle martensite phase will crack more easily than the ferrite phase. Figure 6 shows the difference of crack formation in parts that were produced with and without re-melting every layer. Figure 7 indicates the increase in martensite formation for laser re-melted parts.

\subsection{Density optimization}

Part density is one of the most important physical parameters to optimize, because it has a direct influence on the part's mechanical and physical properties. The part density depends on many process parameters, while this research focuses on the effect of scan speed $v_{s}$, re-melting and the pre-heating temperature T. The influence of these parameters on other properties like hardness and surface roughness has also been studied. 
Numerous test parts were produced with a laser power of $105 \mathrm{~W}$, scan speeds varying from $150 \mathrm{~mm} / \mathrm{s}$ to $550 \mathrm{~mm} / \mathrm{s}$ and pre-heating temperatures of $90^{\circ} \mathrm{C}$ and $200^{\circ} \mathrm{C}$. For some parts, every layer was re-melted with a laser power of $105 \mathrm{~W}$ and scan speed of $200 \mathrm{~mm} / \mathrm{s}$ before adding a new layer. Relative densities of these parts are depicted in Figure 8.

The pre-heating temperature $\mathrm{T}$ also influences the part density. When applying more pre-heating, less heat input is needed from the laser source to melt the powder. That is why, for higher pre-heating temperatures, higher scan speeds can be used to produce equally dense parts. Figure 8 shows that parts produced with a pre-heating of $90^{\circ} \mathrm{C}$ need a scan speed of $500 \mathrm{~mm} / \mathrm{s}$ to result in $98.3 \%$ density. While parts produced with a pre-heating temperature of $200^{\circ} \mathrm{C}$ can be scanned with a scan speed of $550 \mathrm{~mm} / \mathrm{s}$ to get the same density.

\subsection{Surface Roughness}

In this work, only top surface roughness is analyzed. The roughness on the side surface was not taken into consideration here, as it depends on many aspects like for instance the staircase effect [17]. The influence of scan speed on top surface roughness is negligible, within this applied range. To compare surface roughness for parts produced with and without remelting, for different pre-heating temperatures, several parts were produced with identical parameters, resulting in similar part density. As can be seen from the results in Figure 9, the best way to improve top surface quality is to apply re-melting. By re-melting the top layer, the surface roughness can be improved by $47 \%$ (from $18.3 \mu \mathrm{m} R_{a}$ to $8.6 \mu \mathrm{m} R_{a}$ ). Both high pre-heating temperatures and re-melting improve the top surface quality, because they both cause the formation of a stable melt pool. This is also shown in the SEM images of Figure 10. Note that re-melting always increases the total production time, and a good trade-off must be made between productivity and part quality.

\subsection{Hardness}

For conventionally produced M2 HSS parts, the high hardness (of about $65 \mathrm{HRC}$ ) is reached by a post-process hardening heat treatment as defined by ASM [18]. It includes an annealing step at $870-900^{\circ} \mathrm{C}$ followed by hardening for 2 to 5 hours at $1190-1230^{\circ} \mathrm{C}$ and quenching in oil or air.

Rapid cooling rates and high temperatures are typical for the SLM process. The rapid cooling results in rapid solidification of the melt pool and thus a very fine microstructure. Therefore, a relatively high hardness (57 HRC) is achieved for SLM produced M2 HSS parts, without need for a post-process thermal treatment. When every layer is re-melted, the hardness of the final part even increases up to $64 \mathrm{HRC}$. The higher hardness of the re-melted parts is due to the increase of martensite phase. More martensite is formed because the cooling rates are much higher for re-melting (on solid material) than for first time melting (powder material), as shown in XRD measurements (Figure 7). All hardness results are depicted in Figure 11.

\subsection{Tensile properties}

Besides micro-hardness, also other mechanical properties were taken under investigation. Properties like tensile strength and ductility are compared for SLM-produced parts and conventionally produced parts. To reach the optimal mechanical properties (strength and hardness), conventional M2 HSS parts undergo a standardized heat treatment, as defined in section 3.6 .

Tensile tests were performed on three types of tensile bars:

1. Conventionally cast M2 High Speed Steel, cut to the standardized dimensions by EDM.

2. Conventionally cast M2 HSS, cut to dimensions by EDM and furnace heat treated as defined by ASM [18].

3. SLM produced M2 High Speed Steel.

Of each type, five tensile bars were tested and the results in Figure 12 depict a $95 \%$ confidence interval.

As expected, the annealing + hardening treatment results in a more brittle, but stronger material. After heat treatment, the conventionally produced M2 High Speed Steel reaches and ultimate tensile strength of $1620 \pm 283 \mathrm{MPa}$, compared to 804 $\pm 19 \mathrm{MPa}$ without heat treatment.

In the austenitizing step of the heat treatment, the material is heated up close to the melting temperature, to ensure carbide dissolution. Afterwards, during quenching, a brittle martensite phase is formed, enriched with carbon. This causes the high increase in strength and the reduction of the elongation at fracture by a factor of 10 .

In SLM produced parts, there is an inherent heat treatment that takes place during the process, because of the high temperatures that are reached and because of the high cooling rates. This causes the strong but brittle martensite phase to form during the SLM process, as indicated in the XRD measurements in figure 7, leading to tensile test results that aproach the values for conventionally produced and heat treated M2 High speed steel. 


\section{Conclusions}

1. The objective of this study, to produce crack-free M2 HSS parts with a high density by Selective Laser Melting, is achieved. The part with the maximum density of $99.8 \%$ is produced at a pre-heating of $200^{\circ} \mathrm{C}$, a laser power of 105 $\mathrm{W}$, a scan speed of $150 \mathrm{~mm} / \mathrm{s}$ and a hatch spacing of $126 \mu \mathrm{m}$. Lower scan speed, re-melting and higher pre-heating temperature all lead to higher densities. The influence of these parameters on the density is strongly dependent on each other and it is not linear.

2. The best way to improve surface quality on the top surface is to apply re-melting. A top surface roughness of $8.6 \mu \mathrm{m} R_{a}$ has been reached by re-melting.

3. When scanning without re-melting, parameters which lead to a higher density, also lead to a better surface quality.

4. The applications of M2 HSS in mind, a high hardness is very important. The high hardness in conventional HSS M2 is obtained by an aging heat treatment. However, there is already an intrinsic heat treatment in the SLM process due to the typical characteristics of the process, which makes post heat treatment obsolete with SLM. In this study, hardness up to $57 \mathrm{HRC}$ has been reached, without applying a post-treatment. Applying re-melting in every layer, improves the hardness even up to $64 \mathrm{HRC}$, which is comparable to conventional heat treated M2 HSS.

5. Lowering the thermal gradient reduces the thermal stresses and hereby the amount of cracking. Pre-heating of the base plate lowers the thermal gradient. It also lowers the cooling rate, leading to less martensite formation. Re-melting leads to more cracks because the higher cooling rates lead to more formation of a brittle martensite phase. While re-melting every layer induces the same residual stresses, cracking will occur sooner because of the brittle phase.

Similarly, in Shi et al. laser surface treatment was intentionally applied to increase the martensite phase for steel hardening [19].

6. Because of the high temperatures and cooling rates which are reached in the SLM-process, there is an inherent heat treatment that is applied to the SLM-produced parts, leading to a hardness and ultimate tensile strength approaching those of conventionally cast + heat treated parts.

\section{References}

[1] Kruth, J.-P., Froyen, L., Vaerenbergh, J. V., Mercelis, P., Rombouts, M., and B.Lauwers, 2004. "Selective laser melting of iron-based powder". Materials Processing Technology, 149(1), pp. 616-622.

[2] Kempen, K., Yasa, E., Thijs, L., Humbeeck, J. V., and Kruth, J.-P., 2011. "Microstructure and mechanical properties of selective laser melted 18ni-300 steel". Physics Procedia, 12(1), pp. 255-263.

[3] Jamshidinia, M., Kong, F., and Kovacevic, R., 2013. "Numerical modeling of heat distribution in the electron beam melting of ti-6al-4v". Journal of Manufacturing Science and Engineering, 135(6), p. 061010.

[4] Childs, T., Hauser, C., and Badrossamay, M., 2004. "Mapping and modelling single scan track formation in direct metal selective laser melting". CIRP Annals - Manufacturing Technology, 53(1), pp. 191-194.

[5] Niu, H., and Chang, T., 2000. "Selective laser sintering of gas atomized $\mathrm{m} 2$ high speed steel powder". Journal of materials science, 35, pp. 31-38.

[6] Abe, F., Osakada, K., Shiomi, M., Uematsu, K., and Matsumoto, M., 2001. "The manufacturing of hard toold from metallic powders by selective laser melting”. Journal of Materials processing technology, 111(1), pp. 210-213.

[7] Alimardani, M., Toyserkani, E., Huissoon, J., and Paul, C., 2009. "On the delamination and crack formation in a thin wall fabricated using laser solid freeform fabrication process: an experimental-numerical investigation". Optics and lasers in engineering, 47(1), pp. 1160-1168.

[8] Das, S., McWilliams, J., Wu, B., and Beaman, J., 1991. "Design of a high temperature workstation for the selective laser sintering process". In Proceedings of the 2nd Solid Freeform Fabrication Symposium, pp. 164-170.

[9] Das, S., 2003. "Physical aspects of process control in selective laser sintering of metals". Advanced Engineering Materials, 5(10), pp. 701-711.

[10] Hagedorn, Y., Balachandran, N., Meiners, W., Wissenbach, K., and Poprawe, R., 2011. "Slm of net-shaped high strength ceramics: new opportunities for producing dental restorations". In Proceedings of the Solid Freeform Fabrication Symposium, pp. 536-546.

[11] Shiomi, M., Osakada, K., Nakamura, K., T.Yamashita, and F.Abe, 2004. "Residual stress within metallic model made by selective laser melting process". CIRP Annals - Manufacturing technology, 53(1), pp. 195-198.

[12] Mercelis, P., and Kruth, J.-P., 2006. "Residual stresses in selective laser sintering and selective laser melting". Rapid Prototyping Journal, 12(5), pp. 254-265.

[13] GmbH, C. L., 2014. Concept laser. On the WWW, May. http://www.concept-laser.de.

[14] Yasa, E., Deckers, J., and Kruth, J.-P., 2011. "The investigation of the influence of laser re-melting on density, surface quality and microstructure of selective laser melted parts". Rapid Prototyping Journal, 17(5), pp. 312-327.

[15] Technology, L., 2014. Lpw technology ltd. On the WWW, May. http://www.lpwtechnology.com.

[16] Yasa, E., and Kruth, J.-P., 2012. "Microstructural investigation of selective laser melting 3161 stainless steel parts exposed to laser re-melting". Procedia Engineering, 19(1), pp. 389-395. 
[17] Pyka, G., Kerckhofs, G., Papantoniou, I., Speirs, M., Schrooten, J., and Wevers, M., 2013. "Surface roughness and morphology customization of additive manufactured open porous ti6al4v structures”. Materials, 6(10), pp. 4737-4757.

[18] International, A., 1991. ASM Handbook. ASM International, Volume 1:.

[19] Shi, B., and Attia, H., 2013. "Integrated process of laser-assisted machining and laser surface heat treatment". Journal of Manufacturing Science and Engineering, 135(6), p. 061021.

\section{List of Tables}

1 Chemical composition of M2 HSS powder, as reported by material supplier . . . . . . . . . . . . 7

\section{List of Figures}

Fig 1: SEM image of M2 HSS powder.

Fig 2: M2 HSS parts produced by SLM, without pre-heating the baseplate.

Fig 3: The formation of residual stresses due to thermal expansion of underlying layers.

Fig 4: Schematic overview of the pre-heating module.

Fig 5: M2 HSS parts produced with a pre-heating temperature of $90^{\circ} \mathrm{C}$ (left), $150^{\circ} \mathrm{C}$ (middle) and $200^{\circ} \mathrm{C}$ (right).

Fig 6: M2 HSS parts produced with $\mathrm{P}=105 \mathrm{~W}, \mathrm{v}=250 \mathrm{~mm} / \mathrm{s}$ and $\mathrm{h}=128 \mu \mathrm{m}$. Left: only SLM. Right: SLM + re-melting at $200 \mathrm{~mm} / \mathrm{s}$.

Fig 7: XRD measurements of M2 HSS parts produced with and without re-melting of every layer.

Fig 8: Density optimization of M2 HSS parts produced with and without re-melting of every layer, at two different preheating temperatures.

Fig 9: Influence of pre-heating temperature and re-melting on top surface roughness.

Fig 10: Top surface of parts produced with $\mathrm{P}=105 \mathrm{~W}, \mathrm{v}=500 \mathrm{~mm} / \mathrm{s}$. Top: no re-melting, remaining porosity indicated by red circles. Bottom: re-melting at $200 \mathrm{~mm} / \mathrm{s}$.

Fig 11: Hardness of M2 HSS SLM parts compared to conventionally cast parts.

Fig 12: Ultimate tensile strenghth and elongation at fracture for three types of tensile bars. 
Table 1: Chemical composition of M2 HSS powder, as reported by material supplier

\begin{tabular}{lllllllll}
\hline & $\mathrm{Fe}$ & $\mathrm{C}$ & $\mathrm{Mn}$ & $\mathrm{Si}$ & $\mathrm{Cr}$ & $\mathrm{Mo}$ & $\mathrm{W}$ & $\mathrm{V}$ \\
\hline wt\% & Bal. & 0.9 & 0.38 & 0.35 & 3.97 & 4.89 & 6.15 & 1.82
\end{tabular}




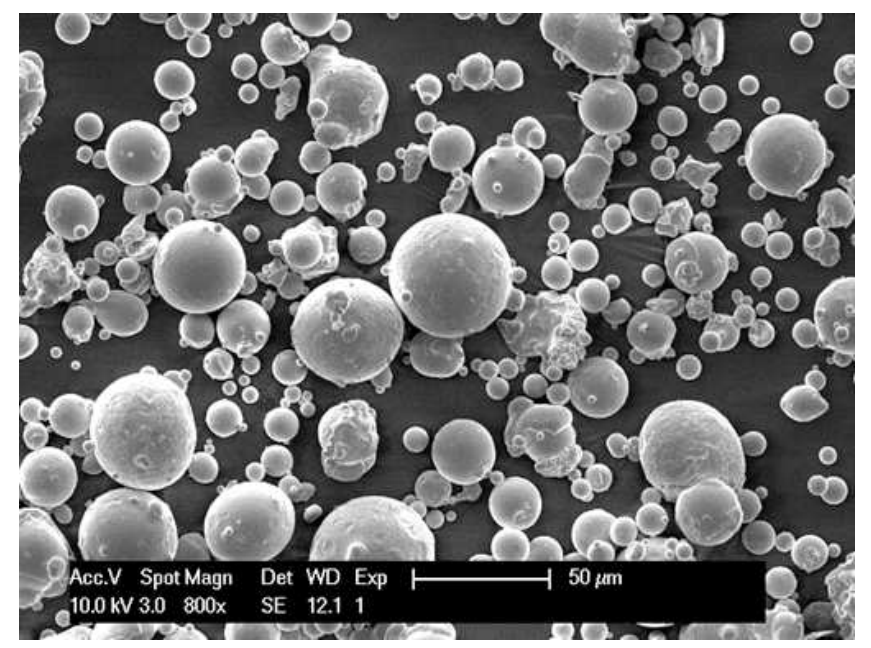

Fig. 1: fig1.ps 


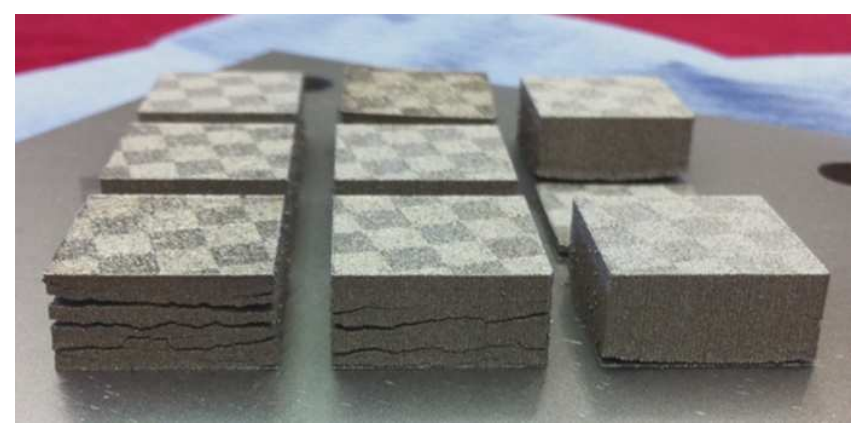

Fig. 2: fig2.ps 


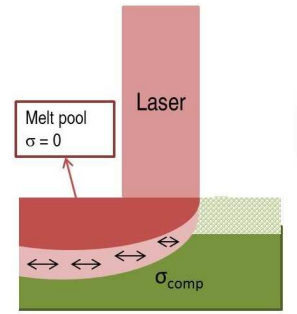

A

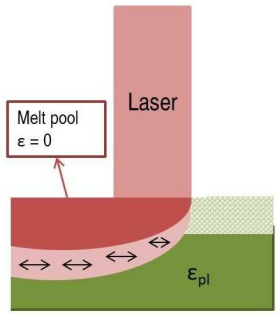

B

Color Code:

Fluid

Solid (heated zone)
Solid (cold)

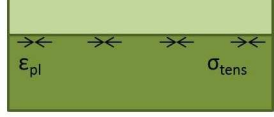

C

Fig. 3: fig3.ps 


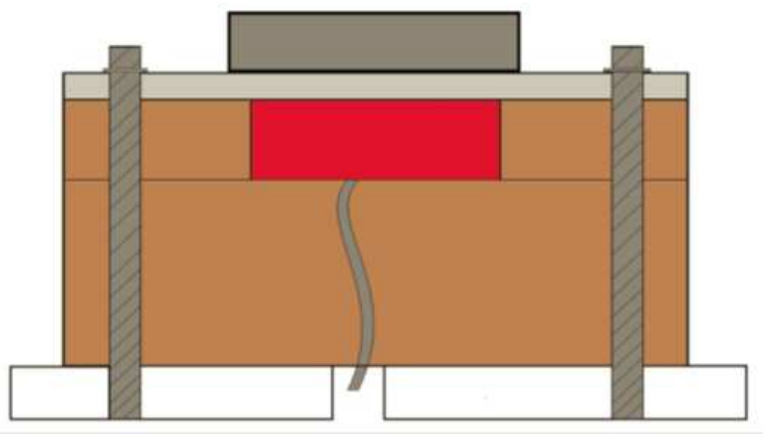

Fig. 4: fig4.ps 


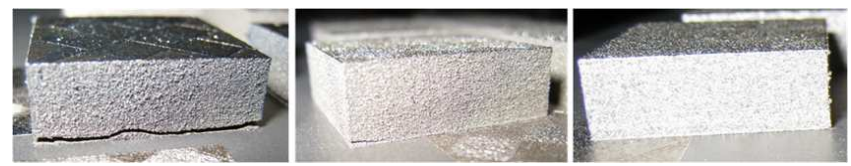

Fig. 5: fig5.ps 


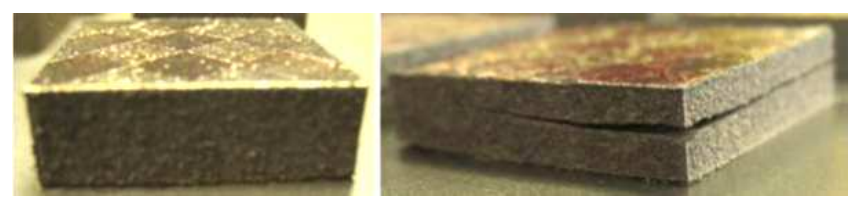

Fig. 6: fig6.ps 


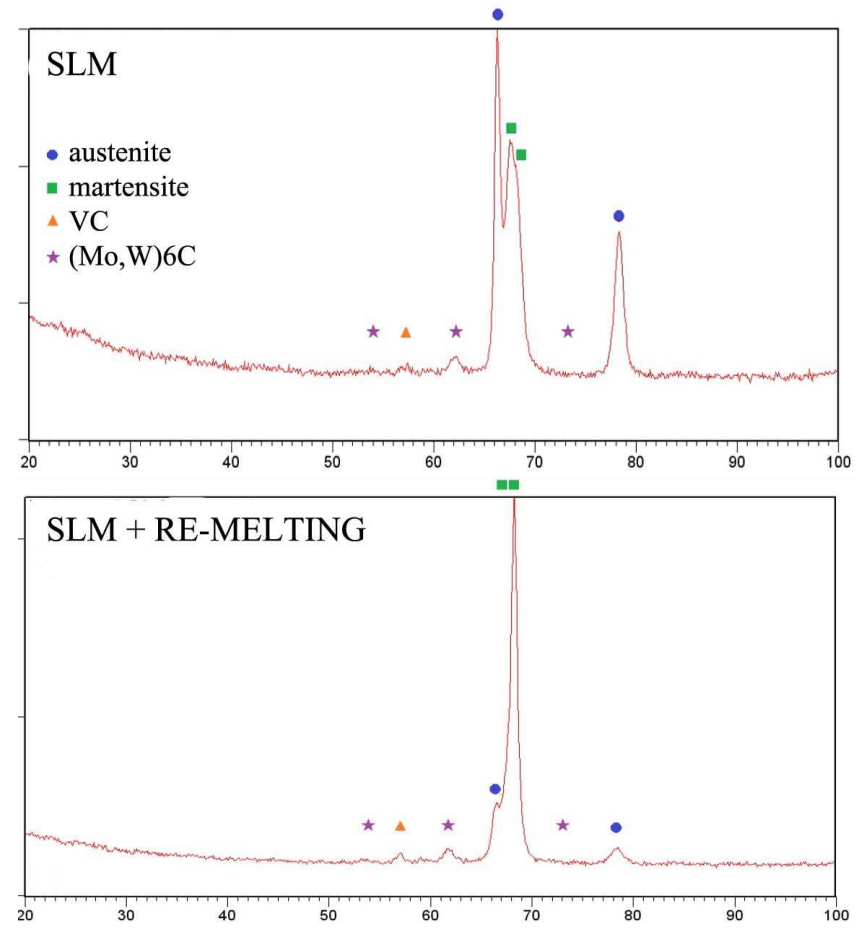

Fig. 7: fig7.ps 


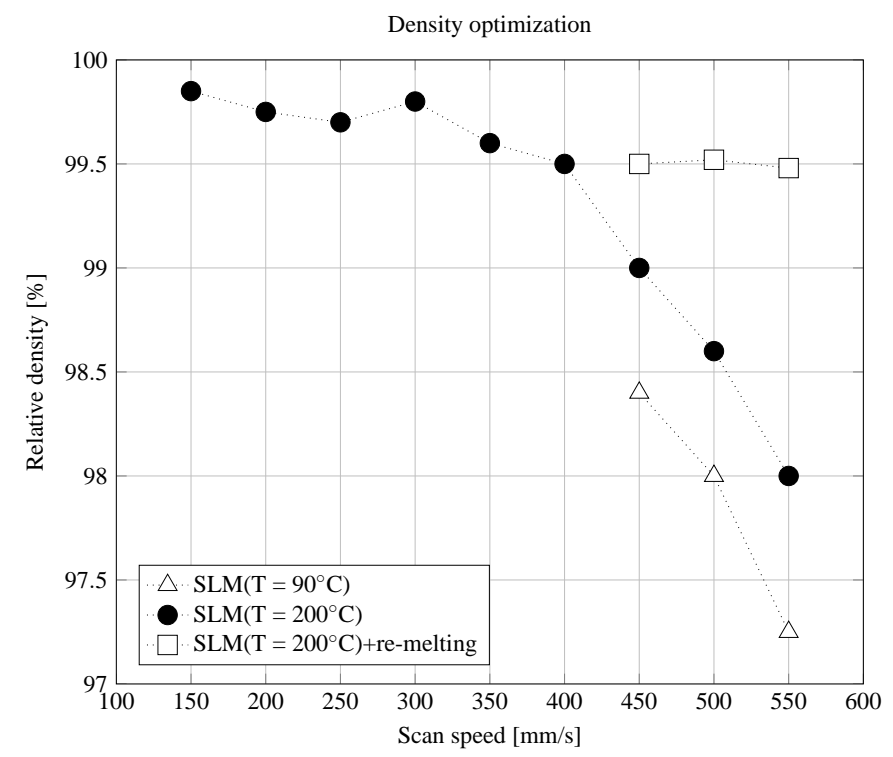

Fig. 8: fig8.tif 


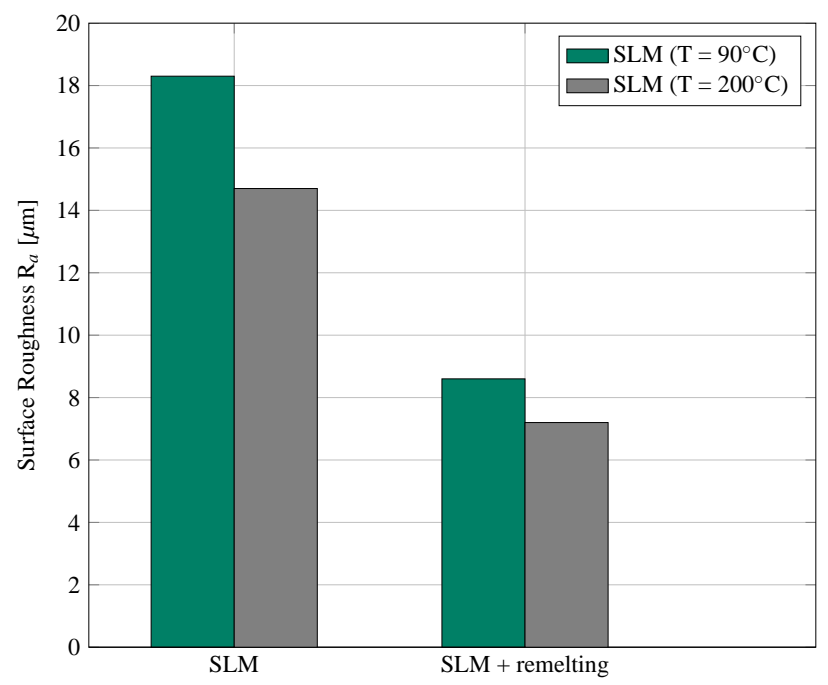

Fig. 9: fig9.tif 


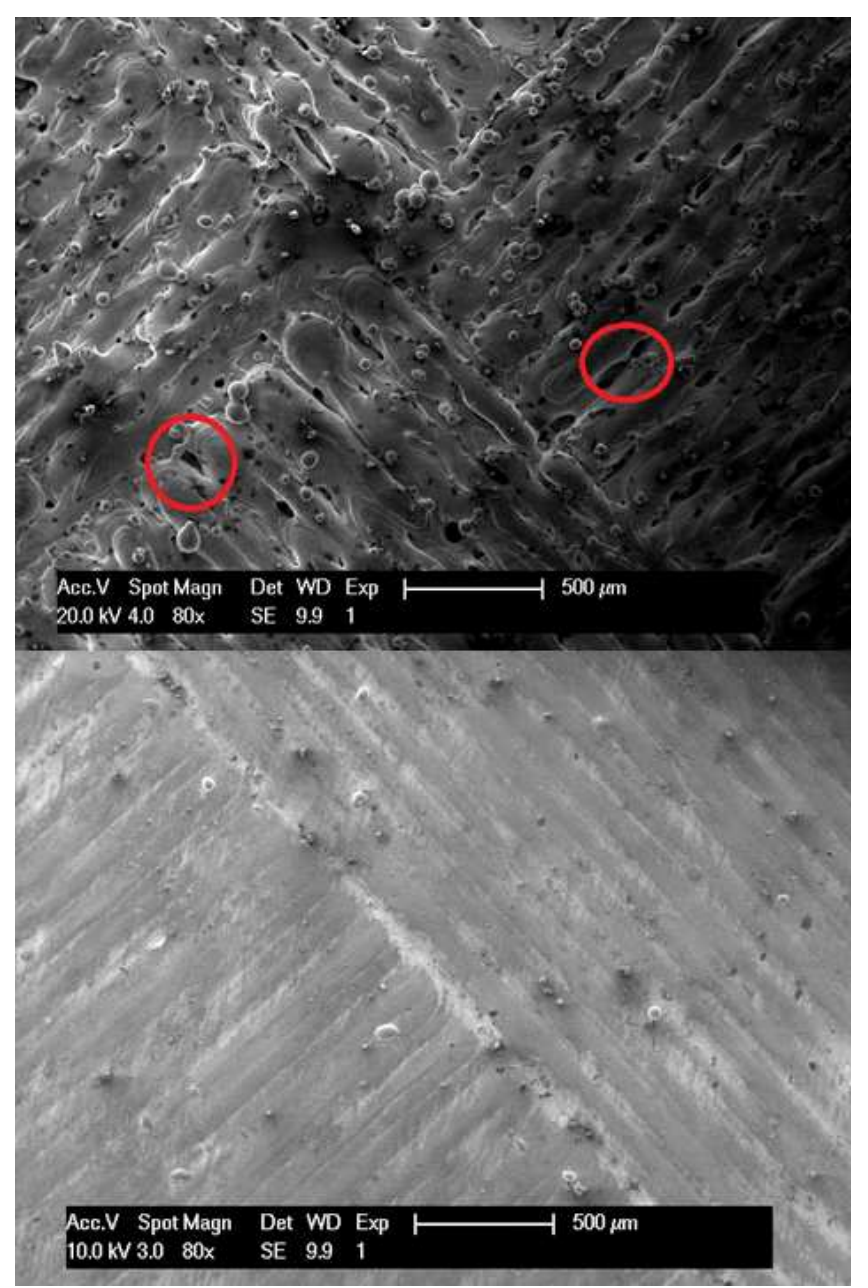

Fig. 10: fig10.ps 


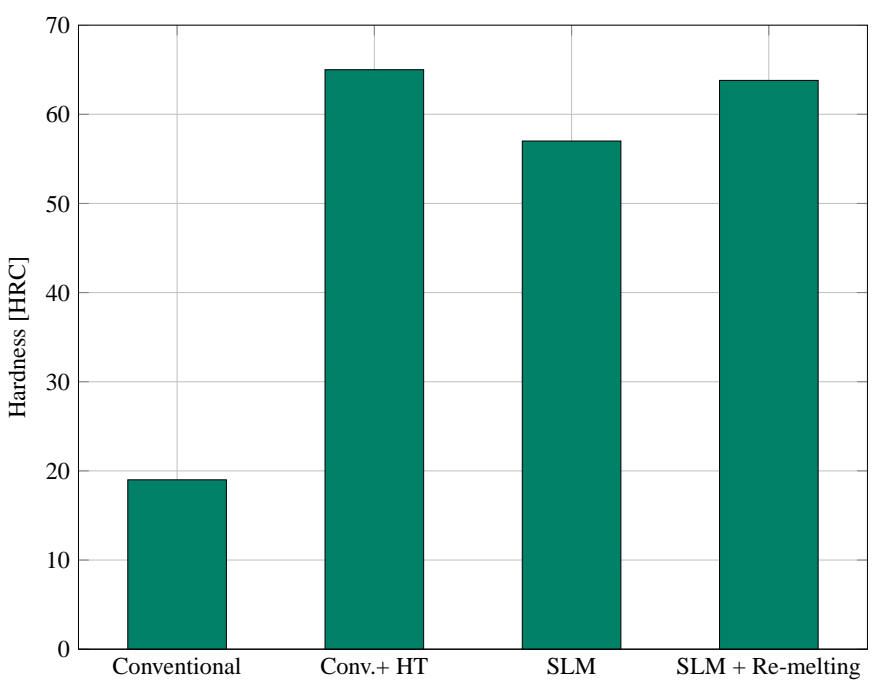

Fig. 11: fig11.tif 


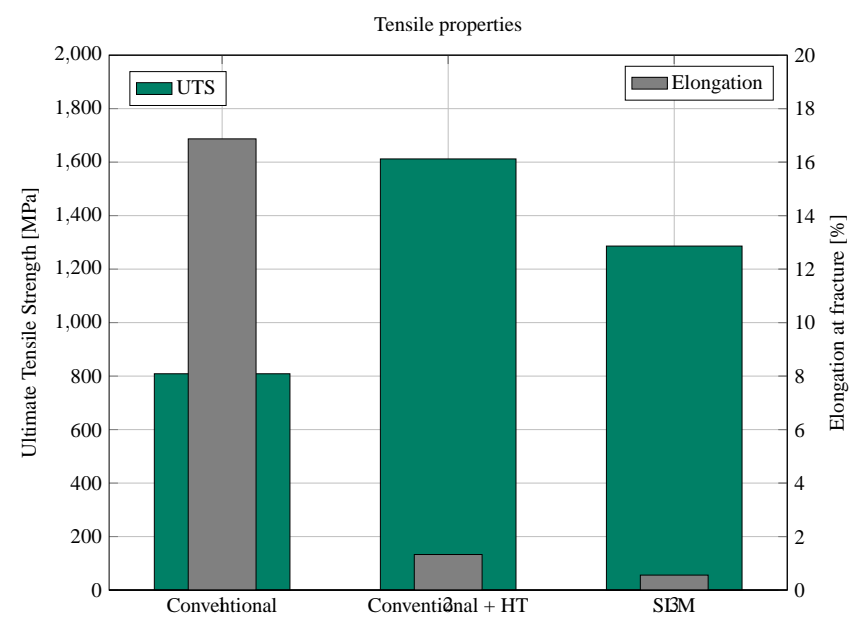

Fig. 12: fig12.tif 